\title{
La lengua heredada y el uso que se hace de ella
}

\author{
Ali Mohamed Laarbi
}

El objetivo principal de este artículo es el de examinar algunas de las peculiaridades del vocabulario utilizado actualmente.

El empleo repetitivo del vocablo "musulmán" en detrímento de "moro" o "turco", responde a que el término "musulmán" es de mayor extension" y, en consecuencia, de menor comprensión. A esto hay que agregar la neutralidad de este vocablo al designar a los miembros de la religión islámica, puesto que Islám significa sumisión a Dios y musulmán quiere decir sumiso.

En la actualidad los términos musulmán y árabe se utilizan sin distinción aunque haya árabes cristianos o judíos.

Entre los más de seiscientos millones de musulmanes que existen hoy, encontramos pertenencias a diferentes etnias que además, tienen como habla otras lenguas. Esto prueba las confusiones que reinan en Europa y que suelen llevar a identificar los dos conceptos; tal confusión es debida al término "árabomusulmán"'.

Fué en Arabia, tras largas luchas entre las árabes, donde tuvo lugar la victoria mahometana, lo que permitió al Islam una expansión rápida y a los árabes una dimensión universal. Las consideraciones históricas sobre su nacimiento confieren un arabismo indeleble. ${ }^{2}$ La etnia árabe está relacionada con el Islam. El profeta del Islam era un profeta árabe, el Corán está escrito en árabe y teóricamente está prohibido traducirlo.

¿Se puede ser musulmán y no árabe? La respuesta sería afirmativa,pero , parafraseando a Massignon, se puede decir que si todo cristiano es un semita teologicamente hablando, todo musulmán no puede ser más que un árabe. ${ }^{3}$ Los pueblos se arabizan en cuanto son conquistados por el Islam, poco importa que

1. La expresión "árabo-musulmán" designa la estrecha concordancia entre dos factores: el énico-nacional y el religioso, con el objetivo de fijar en los árabes, historicamente, una configuración psíquica.

Sobre este término que hay consultar el libro de Hichem Djait: La Personnalité et le devenir arabo-islamiques. Paris, 1974.

2. Bechir Boumaza, Ni emires ni ayatollahs. Madrid, 1984, p. 199.

3. Ibidem. p. 200. 
subsistan entre los musulmanes otras comunidades, el Islam no permite que los territorios bajo su influencia escapen a su control, es decir al control de Alá, mediante el proyecto de integrar al conjunto de la población, con la ayuda de estas tres grandes fuerzas: 1.- La escritura opuesta a la tradición oral de las sociedades segmentarias; 2.- La cultura producida por el clero, opuesta a las culturas llamadas populares; 3.- La ortodoxia profesada por los ulemas para condenar las creencias llamadas herejías. ${ }^{4}$

Es necesario precisar que el Islam no se limita a los ritos, sino que abarca el conjunto de los comportamientos culturales que incluye una ética de la vida. La Sharia ${ }^{5}$ es un conjunto de normas; cuando se sigue, impregna plenamente, los actos y los sentimientos de los musulmanes. Toda costumbre, institución, tiene algún tipo de conexión con la fé. ${ }^{6}$ La Ley sagrada proporciono a pueblos geográficamente dispares los medios necesarios para construir una identidad común compartida, ${ }^{7}$ un modo particular de vivir, de sentir, de manifestarse, con una cierta manera de instalarse en el mundo, de aprehenderlo, que tiene que ver con los modos de percibir y de simbolizar lo que nos rodea. En consecuencia, la mentalidad islámica se caracteriza por la determinación de pertenecer a la comunidad del Islam, lo que constituye el factor más importante para explicar la cohesión emocional de la comunidad.

\section{II}

¿Cuándo se formó la imagen del moro en la consciencia colectiva del pueblo español?

¿Cuándo y cómo se formó la imagen del moro como enemigo tradicional del español y del "arumi" como enemigo tradicional del moro?

Fue a finales del siglo XV, después de la conquista de Granada, cuando en apoyo de la línea política instituida por los Reyes católicos, se forma y constituye la representación del moro como enemigo del espanol. La pragmática de

4. Mohamed Arkoun, "L'islam dans L'histoire", Monde Arabe, Magreb-Machrek, n 102 octubre, noviembre, diciembre, 1983, p. 15.

5. La Sharia es el conjunto de preceptos que deben guiar las vidas pública y privada del musulmán.

6. Daniel Pipes. El Islam de ayer y hoy. Madrid, 1987, p. 63.

7. Ibidem.

8. María Rosa de Madariaga. "Imagen del moro en la memoria colectiva del pueblo español y retorno del moro en la Guerra Civil de 1936", Revista internacional de sociologia, vol. 46, fasc. 4 Oct-Dic. 1988, p. 574-599.

Este artículo es especialmente deudor de las tesis de María Rosa de Madariaga, que ya recogí en un trabajo anterior: "Contribución para la comprensión del africanismo español", Aldaba, Año VIII, $n^{2} 15,1990$, p. 83-88, y donde, por un error de transcripción no aparece citada la profesora María Rosa de Madariaga, cuando mi artículo está claramente inspirado en el suyo citado más arriba, por lo que quiero expresarle públicamente mis más sinceras disculpas. 
1567 encaminada a la total aculturación del grupo morisco agudiza más el problema.

Antes de la ocupación de Granada, no era infrecuente que príncipes y guerreros lucharan juntos contra correligionarios de una u otra de las partes, puesto que la confesionalidad no era la fuerza que motivaba el combate. ${ }^{9}$ En una de las batallas por el Califato de Córdoba, en el año 1010, fueron fuerzas catalanas las que salvaron la situación, y tres obispos dieron su vida por el Amir-principe.

Los cristianos respetaron durante siglos, el Islam en los territorios reconquistados, y la persecución no llegó hasta el siglo XVI, promovida por un clero fanático. La expulsión de los moriscos se debió a razones económicas, y la religión sirvió como estimulante y actuó como fuerza de fanatización psicologica al servicio de la burguesía local que deseaba aprovecharse de la coyuntura política y religiosa para apoderarse de los bienes de los moriscos. ${ }^{10}$

Durante toda la Edad Media, por otra parte, la tolerancia hacia las convicciones del "otro" y el respeto por los sentimientos del enemigo coexistran con las diversas batallas entre moros y cristianos. A pesar de la divergencia lingüística, el respeto por el otro y la estima por sus virtudes se transformaban en un vínculo nacional común. ${ }^{11}$

Con el paso de los siglos, la lucha entre las dos partes fue tomando un matiz cada vez más confesional, y la actitud de los cristianos de siglos posteriores era la de quienes estaban luchando por la verdadera religión contra otra falsa. Por ello, el conflicto adquirió un carácter teológico de enfrentamiento entre las dos religiones. Además la conquista de puertos en las costas del Norte de Africa aunque motivada por la defensa de las rutas comerciales, no vario que los norteafricanos nunca aceptaron tal ocupación y predicaron la guerra santa contra los cristianos en defensa del Islam.

A estas causas se sumaron a partir del siglo XIX otras: La llamada "Guerra de Africa" (1859-60) a la que se dio carácter de "cruzada" religiosa y cuyo eco recogerfa más tarde también la Campana de Melilla de $1893^{12}$ y las denominadas Campañas de Marruecos 1909/12, finalizando con la Guerra del Rif, 1921-26. A estas Campañas hay que añadir la utilización de las tropas marroquíes como arma psicologica contra la joven Segunda República Espafiola, sabiendo el terror que en los soldados espafioles despertaba el moro. He aqui lo que dice de las tropas de Franco, Federica Montseny, en Madrid: "Con ese enemigo sin dignidad ni consciencia, desprovisto del sentimiento espafiol porque si lo tuviera, si

9. Angus Macnab. Esparia bajo la media luna. Barcelona 1988, p. 9.

10. Nicolás Cabrillana, "Rebelión, guerra y expulsión de los moriscos de Almería (15681571). Cuadernos de la Biblioteca Espariola de Tetuan, $n^{2} 13-14$, junio-diciembre, 1976, p. 10.

11. Angus Macnab, Op Cit., p. 10.

12. Tomás García Figueras La acción africana de Esparia en torno al 98. Madrid, 1966, p. 12. 
fuera patriota, no hubiera arrojado en España la legión extranjera y los marroquíes, imponiendo la civilización del "fascio" no como una civilización cristiana sino árabe, de gente que hemos colonizado y que realmente ahora nos coloniza, con unos principios religiosos y unas ideas políticas que hemos de mantener absolutamente alejados de la consciencia de los españoles. ${ }^{13}$

La guerra civil española de 1936 también despertó la imagen que se tenía grabada del moro a través de la Hitoria.

\section{III}

La lengua es el contenido, es el medio, es el mensaje

El término moro que en propiedad se refiere únicamente a los habitantes de la antigua provincia romana de Mauritania, se aplica hoy en día a todos los musulmanes no-árabes.

El empleo de estos vocablos está alejados de los hechos reales, y la ausencia de limites definidos se debe a que no es una terminología cientifica. Estos términos están sometidos a la ambigüedad y a la connotación, la peculiaridad de estos vocablos no estriba en un léxico propio sino en el uso que se hace de ellos como instrumento de accion ideologica. Ejemplos claros son los vocablos: moro, musulmán, turco, y de otro lado; arumi, nasrari, etc.

Mi intención no es la de criticar las incorrecciones linguisticas que cometen los distintos medios de informacion, como tampoco trato de buscar un lenguaje alternativo, sino una alternativa al lenguaje mismo.

La gente en general, y los medios de comunicación en particular, no llegan a socializar el sentido que hay que producir y por eso hay una desmultiplicación del sentido. La dispersión del sentido está en exacta relación con la información.

El lenguaje utilizado por los medios de comunicación, que se impone con las apariencias de la universalidad, quita realidad a todo lo que nombra, y de este modo se esfuerzan por inculcar, leyendas y fantasfas, optando por el estereotipo que se transmite a la gente más desfavorecida culturalmente con la voluntad de tener una opinión ajena a la realidad existente.

\section{IV}

\section{Occidente y Oriente}

Occidente ha adquirido su identidad cultural identificándose en primer lugar con los griegos y los romanos, encontrando hoy día la consciencia polftica

13. Discurso citado en Solidaridad obrera, el 2 de septiembre de 1936, por Vernon Richards. Cfr. Enseignement de la revolution espagnole, Paris 1985, p. 376-77. 
oscilante entre el dualismo tradicional Oriente-Occidente. Para los hombres medievales, el planeta parecía tener dos partes, una cristiana y otra musulmana, siendo este el resultado de un largo proceso cuando europeos y musulmanes fueron a buscar lejos del Mediterráneo su lugar de confrontación.

La situación existencial a nivel mundial impone la necesidad de identificarse oponiéndose al otro. Durante mucho tiempo el árabe ha desempeñado el papel de aquel del que por oposición se afirma el europeo. ${ }^{14}$

Los intelectuales tanto de Occidente como de Oriente saben que existen excepciones en la imagen que se forjan unos de otros, pero eso no cambia la imagen heredada, y la acción secular de poderosos grupos: Clero, ideólogos, intelectuales, predominia, hoy en día y con ello el prejuicio secular que nunca ha perdido su complejidad tradicional, sigue existiendo, en la consciencia colectiva de los pueblos.

\section{V}

¿Cómo podemos transformar el pasado y el presente?

Freire afirma que los hombres no se hacen en el silencio, sino en la palabra, en el diálogo, de ahí que decir la palabra verdadera sea transformar el mundo, ${ }^{15}$ es decir transformar los prejuicios heredados.

14. Abdallah Laroui El Islam árabe y sus problemas. Barcelona 1984, p. 142.

15. P. Freire, Pedagogía del oprimido. Madrid, 1975, p. 103-104. 